\title{
TINGKAT PENGETAHUAN IBU TENTANG MATERI KELAS IBU HAMIL DI PUSKESMAS TEGALREJO KABUPATEN MAGELANG
}

\author{
Fatimah Sari, ${ }^{1}$ Emy Yulianti ${ }^{2}$ \\ ${ }^{1,2}$ D3 Kebidanan STIKes Guna Bangsa Yogyakarta
}

\begin{abstract}
Background : The maternal mortality rate in Indonesia was high and the effort required to reduce maternal mortality - an effort that is associated with pregnancy, parturition and postpartum. One solution is through the study of pregnant women. Class of pregnant woman is a means to learn together about the health of pregnant woman, in the form of face-to -face in a group that aims to improve the mother's knowledge and skill about pregnancy and prenatal care, postpartum care, newborn care, myths, infectious diseases and a birth certificate.
\end{abstract}

Objective : To be known the mother's Knowledge Level about the material class of pregnant women, class of pregnant women definition, Pregnancy, parturition, Postpartum and postpartum family planning, newborn care and infectious diseases at the health center district Tegalrejo Magelang .

Methods : This study used a descriptive study using a cross - sectional approach. The sampling method in this study was the sample saturated with the number of samples in this study were 30 respondents. The research instrument is enclosed questionnaire filled in by the respondent. The analysis used in this study using univariate analysis.

Results : Pregnant woman in the region Tegalrejo health center, Magelang regency in 2013 mostly had a good knowledge amounted to $86.7 \%$ and enough knowledge about the class material amounted to $13.3 \%$.

Conclusion : Mother's level of knowledge about pregnant woman class in Tegalrejo health centers Magelang regency can be categorized good knowledge of as many as 26 respondents ( $86.7 \%$ ).

Keywords : Level of Knowledge, Class of Pregnant Women

\section{PENDAHULUAN}

Salah satu program kesehatan ibu di Jawa Tengah yang telah mengikuti kelas ibu hamil. Menurut Sie KESGA Dinas Kesehatan Magelang kegiatan kelas ibu hamil sudah dicanangkan sejak tahun 2010. Saat ini 21 kecamatan sudah melaksanakan kelas ibu hamil. Kecamatan Tegalrejo merupakan salah satu kecamatan di Kabupaten Magelang yang terdiri dari 21 desa. Puskesmas Tegalrejo merupakan unit pelayanan kesehatan yang berada di wilayah Kecamatan Tegalrejo. Kegiatan kelas ibu hamil di Puskesmas Tegalrejo baru dilaksanakan pada tahun 2011. Saat itu hanya 2 desa yang melaksanakan kegiatan kelas ibu hamil.

Dari data KIA Puskesmas Tegalrejo pada tahun 2011 terdapat 2 kematian ibu bersalin yaitu pada bulan Pebruari seorang primigravida meninggal karena menderita penyakit jantung dan pada bulan November seorang multigravida meninggal karena mengalami perdarahan setelah menjalani operasi seksio cesaria. Hal itu disebabkan karena ketidak tahuan ibu hamil tersebut tentang tanda bahaya 
pada kehamilan dan persalinan. Untuk itu diperlukan suatu strategi yang efektif untuk menyebarluaskan informasi yang berhubungan dengan kesehatan ibu dan anak. yang diharapkan turut berperan dalam menurunkan angka kesakitan dan kematian akibat kehamilan, persalinan dan nifas adalah pemakaian buku KIA.

Buku KIA adalah suatu buku yang berisi catatan kesehatan lbu dan Anak serta informasi cara menjaga kesehatan dan mengatasi anak sakit.Namun tidak semua ibu mau/bisa membaca buku KIA, Penyebabnya bermacam-macam, ada ibu yang tidak punya waktu untuk membaca buku KIA, atau malas membaca buku KIA, sulit mengerti isi buku KIA, ada pula ibu yang tidak dapat membaca. Oleh sebab itu ibu hamil perlu diajari tentang isi buku KIA dan cara menggunakan buku KIA.

Salah satu solusinya yaitu melalui penyelenggaraan Kelas lbu Hamil untuk ibu hamil (A.A Hidayat, 2009). Kelas ibu hamil merupakan sarana untuk belajar bersama tentang kesehatan bagi ibu hamil, dalam bentuk tatap muka dalam kelompok yang bertujuan untuk meningkatkan pengetahuan dan ketrampilan ibu-ibu mengenai kehamilan, perawatan kehamilan, persalinan, perawatan nifas, perawatan bayi baru lahir, mitos, penyakit menular dan akte kelahiran. Kelas ibu hamil adalah kelompok belajar ibu-ibu hamil dengan umur kehamilan antara 4 minggu s/d 36 minggu dengan jumlah peserta maksimal 10 orang (Kementerian Kesehatan RI, 2011).

Pada tahun 2011 di Jawa Tengah dibentuk 2.508 kelas ibu hamil, walaupun demikian tidak ada angka yang secara pasti menyebutkan jumlah ibu di Jawa Tengah yang telah mengikuti kelas ibu hamil. Menurut Sie KESGA Dinas Kesehatan Magelang kegiatan kelas ibu hamil sudah dicanangkan sejak tahun 2010. Saat ini 21 kecamatan sudah melaksanakan kelas ibu hamil. Kecamatan Tegalrejo merupakan salah satu kecamatan di Kabupaten Magelang yang terdiri dari 21 desa. Puskesmas Tegalrejo merupakan unit pelayanan kesehatan yang berada di wilayah Kecamatan Tegalrejo. Kegiatan kelas ibu hamil di Puskesmas Tegalrejo baru dilaksanakan pada tahun 2011. Saat itu hanya 2 desa yang melaksanakan kegiatan kelas ibu hamil.

Strategi yang dipilih oleh Puskesmas Tegalrejo adalah kegiatan kelas ibu hamil. Salah satu target yang ingin dicapai Kecamatan Tegalrejo pada tahun 2013 adalah tidak ada kematian ibu bersalin, sehingga terobosan yang dilakukan dengan direncanakan semua desa di wilayah Puskesmas Tegalrejo melaksanakan kegiatan kelas ibu hamil.

Menurut seksi KIA Puskesmas Tegalrejo sampai dengan bulan Agustus 2013 sudah semua desa melaksanakan kegiatan kelas ibu hamil. Menurut hasil studi pendahuluan pada bulan Agustus tahun 2013 yang peneliti lakukan di Desa Purwosari Kecamatan Tegalrejo, dari 10 ibu hamil yang mengikuti kegiatan kelas ibu hamil terdapat 7 orang primigravida dan 3 orang multigravida. Dari hasil pra-tes dan pascates didapatkan hasil 2 orang primigravida mengalami peningkatan pengetahuan $10 \%, 3$ orang primigravida mengalami peningkatan pengetahuan 20\%, 2 orang primigravida mengalami peningkatan $30 \%$, dari 3 orang multigravida masing-masing mengalami peningkatan pengetahuan $10 \%, 15 \%$, $30 \%$.

\section{PEMBAHASAN}

1. Karakteristik Ibu

Karakteristik Ibu diperoleh hasil sebagian besar ibu berusia 20 sampai 35 tahun yaitu sebanyak 22 (73,3\%), sebagian besar ibu berpendidikan SMP dan SMA yaitu masing-masing sebanyak $13(43,3 \%)$ ibu, merupakan ibu rumah tangga yaitu sebanyak 28 (93,3\%), sebagian besar umur kehamilan ibu masuk trimester III yaitu sebanyak 28 $(93,3 \%)$ dan sebagian besar ibu berstatus paritas dua yaitu sebanyak 11 (36,7\%). bahwa bila seseorang mampu menjawab pertanyaan-pertanyaan mengenai bidang tertentu dengan lancar, baik lisan maupun tulisan, maka dia dapat dikatakan mengetahui bidang tersebut.

Pertanyaan-pertanyaan tentang materi kelas lbu hamil dengan baik. Hal ini 
sesuai dengan pendapat Notoatmodjo (2003).

2. Tingkat Pengetahuan lbu Hamil Tentang Materi Kelas Ibu Hamil

\begin{tabular}{cccc}
\hline No & $\begin{array}{c}\text { Tingkat pengetahuan } \\
\text { Materi Kelas Ibu } \\
\text { Hamil }\end{array}$ & $\mathbf{F}$ & $\%$ \\
\hline 1 & Baik & 26 & 86,7 \\
2 & Cukup & 4 & 13,3 \\
3 & Kurang & 0 & 0 \\
\hline
\end{tabular}

$\begin{array}{lrr}\text { Jumlah } & 30 & 100\end{array}$

Sumber data primer 2013

Berdasarkan data dari hasil tabulasi data diperoleh hasil sebagian besar pengetahuan ibu tentang materi kelas ibu hamil adalah baik, yaitu sebanyak 26 $(86,7 \%)$. Hal ini menunjukkan bahwa pengetahuan ibu tentang materi kelas ibu hamil sudah baik.hal ini ditunjukkan dengan tingkat pengetahuan yang baik tentang materi kelas Ibu Hamil

3. Tingkat Pengetahuan tentang kelas Ibu Hamil

\begin{tabular}{cccl}
\hline No & $\begin{array}{c}\text { Tingkat pengetahuan } \\
\text { tentang Kelas lbu Hamil }\end{array}$ & F & $\%$ \\
\hline 1 & Baik & 21 & 70 \\
2 & Cukup & 9 & 30 \\
3 & Kurang & 0 & 0 \\
\hline
\end{tabular}

\begin{tabular}{lll} 
Jumlah & 30 & 100 \\
\hline Sumber
\end{tabular}

Sumber data primer 2013

Berdasarkan data dari tabel 4.3 diperoleh hasil sebagian besar pengetahuan ibu tentang kelas ibu hamil adalah baik, yaitu sebanyak 21 (70\%). Berdasarkan hasil tabulasi data diperoleh hasil sebagian besar pengetahuan ibu tentang kelas ibu hamil adalah baik, yaitu sebanyak 21 (70\%).

Semua ibu mampu menjawab dengan benar pada pernyataan bahwa materi yang diberikan dalam kelas ibu hamil antara lain materi tentang kehamilan, persalinan, perawatan nifas dan KB perawatan bayi baru lahir, penyakit menular dan tujuan diadakannya kelas ibu hamil adalah untuk meningkatkan pengetahuan ibu mengenai kehamilan, persalinan, nifas, $\mathrm{KB}$, perawatan bayi, serta penyakit menular. Ini menunjukkan bahwa ibu sudah paham tentang kelas ibu hamil serta tujuan diadakannya pelatihan kelas Ibu hamil. lbu banyak menjawab salah pada pernyataan tentang keikutsertaan suami dalam pelaksanaan kelas ibu hamil, karena ibu hanya mengetahui jika kelas ibu hamil hanya diikuti oleh ibu hamil, sedangkan menurut Kemenkes RI (2011) kelas ibu hamil dapat pula diikuti oleh suami / keluarga ikut serta minimal 1 kali pertemuan sehingga dapat mengikuti berbagai materi yang penting, misalnya materi tentang persiapan persalinan atau materi yang lainnya.

Tabel 4. Tingkat pengetahuan tentang kehamilan

\begin{tabular}{cccc}
\hline No & $\begin{array}{c}\text { Tingkat pengetahuan } \\
\text { tentang Kehamilan }\end{array}$ & $\mathbf{F}$ & $\%$ \\
\hline 1 & Baik & 21 & 70 \\
2 & Cukup & 8 & 26,7 \\
3 & Kurang & 1 & 3,3 \\
\hline
\end{tabular}

$\begin{array}{lrr}\text { Jumlah } & 30 & 100 \\ \text { Sumber : Data Primer } 2013\end{array}$

Berdasarkan hasil tabulasi data diperoleh hasil sebagian besar pengetahuan ibu tentang kehamilan adalah baik, yaitu sebanyak 21 (70\%) ibu. lbu banyak mengetahui bahwa kehamilan adalah masa dimana terdapat janin di dalam rahim seorang perempuan dan bengkak di kaki dan tangan disertai sakit kepala yang hebat merupakan hal yang berbahaya dalam kehamilan. Hal ini menunjukkan bahwa ibu telah mengetahui pengertian dari kehamilan dan tanda bahaya pada saat masa kehamilan. satu pertanyaan yang banyak dijawab salah oleh ibu yaitu ibu menganggap bahwa air es membuat tubuh bayi besar sehingga sulit di lahirkan. Hal ini menunjukkan bahwa ibu tidak menguasai salah satu materi kelas ibu hamil yang salah satunya adalah membahas masalah mitos/kepercayaan/ adat istiadat setempat yang berkaitan dengan kesehatan ibu dan anak. 
Tabel 5. Tingkat Pengetahuan lbu tentang Persalinan di Puskesmas Tegal Rejo

\begin{tabular}{cccc}
\hline No & $\begin{array}{c}\text { Tingkat pengetahuan } \\
\text { tentang Persalinan }\end{array}$ & $\mathbf{F}$ & $\%$ \\
\hline 1 & Baik & 28 & 93.3 \\
2 & Cukup & 2 & 6,7 \\
3 & Kurang & 0 & 0 \\
\hline
\end{tabular}

$\begin{array}{lrr}\text { Jumlah } & 30 & 100\end{array}$

Sumber : Data Primer 2013

Berdasarkan data dari tabel 5 diperoleh hasil sebagian besar pengetahuan ibu tentang persalinan adalah baik, yaitu sebanyak 28 (93,3\%). Salah satu pertanyaan yang $100 \%$ dijawab benar oleh lbu adalah tandatanda persalinan adalah mulas-mulas yang teratur timbul semakin sering dan semakin lama merupakan tanda dari persalinan, hal ini dikarenakan materi yang diberikan dalam kegiatan kelas ibu hamil adalah membahas tentang tandatanda persalinan (Kemenkes RI, 2011).

Tabel 6. Tingkat pengetahuan lbu tentang Nifas dan KB pasca salin.

\begin{tabular}{llcc}
\hline No & $\begin{array}{c}\text { Tingkat pengetahuan } \\
\text { tentang nifas dan KB } \\
\text { pasca salin }\end{array}$ & $\mathbf{F}$ & $\%$ \\
\hline 1 & Baik & 27 & 90 \\
2 & Cukup & 2 & 6,7 \\
3 & Kurang & 1 & 3,3 \\
\hline Jumlah & & 30 & 100 \\
\hline
\end{tabular}

Sumber : Data Primer 2013

Berdasarkan data dari tabel 6 diperoleh hasil sebagian besar pengetahuan ibu tentang nifas dan KB pasca salin adalah baik, yaitu sebanyak 27 (90\%). lbu banyak menjawab benar bahwa waktu yang tepat untuk ber-KB yaitu 40 hari setelah melahirkan, hal ini dikarenakan dalam materi kelas ibu hamil diberikan materi tentang perawatan masa nifas dan KB pasca persalinan (Kemenkes $\mathrm{RI}, 2011)$. Pada pelaksanaan kelas ibu hamil KB pasca persalinan dapat dikonsultasikan ke bidan/dokter dalam memilih cara KB yang paling sesuai dengan kondisi suami istri dan aman bagi ibu menyusui serta dalam memilih kontrasepsi atas kesepakatan suami istri. Waktu yang tepat untuk ber KB yaitu selama masa nifas.

Tabel 7. Tingkat Pengetahuan ibu tentang Perawatan Bayi Baru Lahir

\begin{tabular}{lccc}
\hline No & $\begin{array}{c}\text { Tingkat pengetahuan } \\
\text { tentang perawatan BBL }\end{array}$ & $\mathbf{F}$ & $\%$ \\
\hline 1 & Baik & 21 & 70 \\
2 & Cukup & 9 & 30 \\
3 & Kurang & 0 & 0 \\
\hline \multirow{2}{*}{ Jumlah } & & 30 & 100 \\
\hline
\end{tabular}

Sumber : Data Primer 2013

Berdasarkan data dari tabel 7 diatas diperoleh hasil sebagian besar pengetahuan lbu tentang perawatan bayi baru lahir adalah baik, yaitu yaitu sebanyak $21(70 \%)$.

Jawaban responden banyak menjawab benar tentang tanda-tanda bayi sehat yaitu tubuh bayi kemerahan disertai gerakan aktif merupakan tanda bayi baru lahir sehat. Hal ini menunjukkan bahwa ibu sudah memahami materi tentang tanda bayi baru lahir sehat. Jawaban salah banyak terdapat pada pernyataan bahwa imunisasi merupakan upaya untuk melindungi bayi dari seluruh penyakit, sedangkan dalam materi kelas ibu hamil diberitahukan bahwa imunisasi merupakan upaya wajib untuk melindungi bayi dari berbagai penyakit menular (Kemenkes RI, 2011). Ini menujukan bahwa ibu kurang memahami tentang materi imunisasi.

Tabel 8. Tingkat Pengetahuan ibu tentang Penyakit menular

\begin{tabular}{lccc}
\hline No & $\begin{array}{c}\text { Tingkat pengetahuan } \\
\text { tentang penyakit menular }\end{array}$ & $\mathbf{F}$ & $\%$ \\
\hline 1 & Baik & 14 & 46,7 \\
2 & Cukup & 16 & 53,3 \\
3 & Kurang & 0 & 0 \\
\hline \multirow{2}{*}{ Jumlah } & & 30 & 100 \\
\hline
\end{tabular}

Sumber : Data Primer 2013 
yang $\begin{array}{r}\text { Berdasarkan hasil tabulasi data } \\ \text { diperoleh sebagian besar }\end{array}$ pengetahuan lbu tentang penyakit menular adalah cukup yaitu sebanyak 16 (53,3\%). Hal ini menunjukkan bahwa ibu belum memahami tentang materi penyakit menular, tetapi meskipun ibu memiliki pengetahuan yang kurang tentang penyakit menular tetapi ibu mengetahui penyakit HIV/AID tidak dapat ditularkan melalui batuk atau bersin dan perabaan serta ibu mengetahui bahwa pencegahan penyakit malaria dapat dilakukan dengan tidur memakai kelambu dan memasang kassa nyamuk pada lubang angin di rumah.

Hasil Tabulasi silang didapatkan : Tingkat pengetahuan ibu tentang materi kelas ibu hamil berdasarkan karakteristik umur di Puskesmas Tegalrejo. Berdasarkan data datas diperoleh gambaran semua ibu hamil dengan usia < 20 tahun sebanyak 3 (3\%) responden dengan kategori tingkat pengetahuan baik, dan dari 22 ibu hamil dengan umur 20-35 tahun sebanyak 18 (60\%) responden, dan semua ibu hamil dengan umur 35 tahun sebanyak 5 (16,7\%) responden.

Tingkat pengetahuan ibu tentang materi kelas ibu hamil berdasarkan karakteristik pendidikan di Puskesmas Tegalrejo. Berdasarkan data diatas diperoleh hasil 3 ibu hamil pendidikan SD dengan kategori cukup sebanyak 2 $(6,7 \%)$ responden, dari 13 ibu hamil dengan pendidikan SMP sebagian besar dengan tingkat pengetahuan baik sebanyak $11(36,7 \%)$ responden, dan dari 13 ibu hamil dengan pendidikan SMA sebagian besar dengan tingkat pengetahuan baik sebanyak 13 (43,3\%) responden, dan 1 responden dengan pendidikan perguruan tinggi dengan kategori pengetahuan baik.

Tingkat pengetahuan ibu tentang materi kelas ibu hamil berdasarkan karakteristik pekerjaan di Puskesmas Tegalrejo. Berdasarkan karakteristik pekerjaan ibu dari 28 ibu hamil yang bekerja sebagai ibu rumah tangga sebagian besar dengan pengetahuan baik sebanyak 24 (80\%) responden, dan sebanyak 1 ibu hamil masing- masing yang bekerja sebagai pegawai swasta dan guru memiliki kategori tingkat pengetahuan baik.

Tingkat pengetahuan ibu tentang materi kelas ibu hamil berdasarkan karakteristik usia kehamilan di Puskesmas Tegalrejo. Berdasarkan usia kehamilan ibu diperoleh hasil 2 ibu hamil dengan usia kehamilan trimester II dengan tingkat pengetahuan baik, dan dari 28 ibu hamil dengan trimester III sebagian besar dengan tingkat pengetahuan baik sebanyak 24 (80\%) responden.

Tingkat pengetahuan ibu tentang materi kelas ibu hamil berdasarkan karakteristik paritas di Puskesmas Tegalrejo. Berdasarkan karakteristik paritas ibu diperoleh hasil semua ibu hamil dengan paritas satu dan dua masing-masing sebanyak $10 \quad(33,3 \%)$ responden dengan kategori pengetahuan baik, dan dari 9 ibu hamil dengan paritas $>3$ sebagian besar dengan tingkat pengetahuan baik sebanyak 6 (20\%) responden.

\section{KESIMPULAN}

1. Karakteristik ibu sebagian besar berusia 20-35 tahun yaitu sebanyak $22(73,3 \%)$, berpendidikan SMP dan SMA yaitu masing-masing sebanyak

13 (43,3\%), merupakan ibu rumah tangga yaitu sebanyak $28(93,3 \%)$, usia kehamilan trimester III yaitu sebanyak 28 (93,3\%), dan berstatus paritas dua yaitu sebanyak 11 $(36,7 \%)$.

2. Pengetahuan ibu tentang materi kelas ibu hamil di Puskesmas Tegalrejo adalah baik, yaitu sebanyak 26 (86,7\%).

3. Pengetahuan ibu tentang kelas ibu hamil di Puskesmas Tegalrejo adalah baik, yaitu sebanyak 21 (70\%).

4. Pengetahuan ibu tentang kehamilan di Puskesmas Tegalrejo adalah baik, yaitu sebanyak 21 (70\%).

5. Pengetahuan ibu tentang persalinan di Puskesmas Tegalrejo adalah baik, yaitu sebanyak $28(93,3 \%)$

6. Pengetahuan ibu tentang nifas dan KB pasca salin di 
Puskesmas Tegalrejo adalah baik, yaitu sebanyak 27 (90\%).

7. Pengetahuan Ibu tentang perawatan Bayi Baru Lahir di Puskesmas Tegalrejo adalah baik, yaitu sebanyak $21(70 \%)$.

8. Pengetahuan ibu tentang penyakit menular di Puskesmas Tegalrejo adalah cukup, yaitu sebanyak $16(53,3 \%)$.

\section{SARAN}

1. Untuk Bidan

Meningkatkan peran serta bidan sebagai petugas kesehatan yang terjun di masyarakat dan bekerja sama dengan kader serta tokoh masyarakat, serta meningkatkan kerja sama lintas program dengan mengikutsertakan petugas lain dalam pelaksanaan kelas ibu hamil.

2. Untuk Ibu Hamil

lbu hamil lebih meningkatkan pengetahuan tentang seputar masalah kehamilan, persalinan dan nifas dengan terus mengikuti kegiatan kelas ibu hamil untuk menunjang keselamatan dan kesehatan ibu serta janin dalam kandungan.

3. Untuk Penelitian Selanjutnya

Bagi peneliti selanjutnya diharapkan dapat meneliti variabel lain yang lebih luas yang berkaitan dengan materi kelas ibu hamil dan dengan responden yang lebih banyak.

\section{DAFTAR PUSTAKA}

A.Aziz Alimul Hidayat (2009). Pengantar Kesehatan Anak untuk Pendidikan Bidan. Jakarta: Salemba Medika.

Arikunto,S. (2010). Prosedur Penelitian : Suatu Pendekatan Praktek. Jakarta : Rinneka Cipta.

Azwar, A. dan Prihartono, J (2003). Metodologi Penelitian Kedokteran dan Kesehatan Masyarakat. Jakarta : Binarupa Aksara.
BKKBN (2006). Deteksi Dini Komplikasi Persalinan. Jakarta : Depkes RI Budiarto ( 2002). Biostatistik Untuk Kedokteran dan Kesehatan Masyarakat. Jakarta : EGC.

Depkes RI (2009. a). Pedoman Pelaksanaan Kelas lbu Hamil. Jakarta : Depkes RI .

Depkes RI (2009. b). Pegangan Fasilitator Kelas Ibu Hamil. Jakarta : Depkes RI.

Historiyati, D. (2011). Hubungan Pengetahuan dan Sikap lbu Hamil Tentang Kelas lbu Hamil dengan Persepsi dalam Kelas Ibu Hamil di wilayah Kerja Puskesmas Tumbeleng. Karya Tulis IImiah. Poltekkes Semarang.

Hidayat, A. (2010). Metode Penelitian Kebidanan dan Teknik Analisis Data. Jakarta : Salemba Medika.

Kementerian Kesehatan RI (2011. a). Pedoman Pelaksanaan Kelas lbu Hamil. Jakarta : Kemenkes RI.

Kementerian Kesehatan RI (2011. b). Profil Kesehatan Indonesia 2010. Jakarta : Kemenkes RI.

Manuaba, I.B.G (2009). Memahami Kesehatan Reproduksi Wanita. Jakarta : EGC

Meilani, dkk (2009). Kebidanan Komunitas. Yogyakarta

Fitramaya.

Notoatmodjo. S (2007). Promosi Kesehatan dan IImu Perilaku. Jakarta : Rineka Cipta.

Notoatmodjo. S (2010). Metodologi Penelitian Kesehatan. Jakarta : Rineka Cipta.

Osninelli,R. (2007). Persepsi lbu Hamil Tentang Kelas Ibu Hamil di Desa Sidomulyo Wilayah Kerja Puskesmas Megaluh Kabupaten 
Tanah Datar Tesis.UGM

Yogyakarta.

Riwidikdo, H (2009). Statistik Kesehatan. Jogjakarta : Mitra Cendekia Sugiyono (2011). Statistika Untuk Penelitian. Bandung : Alfa Beta Varney, H. (2006). Buku Ajar
Asuhan Kebidanan. Jakarta : EGC.

Wawan dan Dewi. (2010). Pengetahuan, Sikap dan Perilaku Manusia. Yogjakarta : Nuha Medika. 